\title{
Role of the Tympanometric Gradient and Acoustic Reflex on Prognosis of Otitis Media With Effusion
}

\author{
Nihat Susaman $\mathbb{B}$, Hasan Cetiner $(\mathbb{D}$ \\ Department of Otorhinolaryngology, Elazig Education and Research Hospital, Elazig, Turkey
}

ORCID iDs of the authors: N.S. 0000-0002-8890-069X; H.C. 0000-0002-72I8-6217.

Cite this article as: Susaman N, Cetiner H. Role of the Tympanometric Gradient and Acoustic Reflex on Prognosis of Otitis Media With Effusion. Cyprus J Med Sci 2021; 6(1): 30-3.

\section{BACKGROUND/AIMS}

Otitis media with effusion (OME) is a major health issue worldwide. Although it is difficult to consider any quantitative measurement in particular to be a herald of clinical recovery in $\mathrm{OME}$, this study aimed to determine the role of tympanometric quantitative values, especially gradient (GR) and acoustic reflex (AR), in patients with OME who are approaching the full healing stage.

\section{MATERIAL and METHODS}

Based on the tympanic membrane findings, participants were divided into 2 groups: (A) minimal retraction group and (B) normal group. For each group, the tympanometric quantitative measurements (static compliance [SC], tympanometric peak pressure [TPP], GR, and $A R$ ) were obtained and compared statistically. In addition, the relationship of AR with tympanometric quantitative measurements was compared statistically.

\section{RESULTS}

The mean GR values in group $A(n=66)$ and group $B(n=73)$ were $157.06 \pm 92.85$ daPa and $103.60 \pm 28.51$ daPa, respectively $(P=.001)$. Although no significant difference was found with respect to $A R$, statistically significant differences were observed with respect to TPP between the 2 groups.

\section{CONCLUSION}

In contrast to AR, GR and TPP values were consistent with the examination findings of the tympanic membrane observed in patients with resolved OME progressing to the full healing stage. Thus, these 2 tympanometric quantitative measurements are beneficial for the diagnosis and follow-up of patients with OME.

Keywords: Tympanometry, otitis media, acoustic reflex

\section{INTRODUCTION}

Otitis media with effusion (OME) is defined as the presence of fluid in the middle ear without signs or symptoms of an acute ear infection. The tympanic membrane is often cloudy with distinctly impaired mobility, and an air-fluid level or bubble may be visible in the middle ear (I). OME may occur during an upper respiratory infection, spontaneously because of poor Eustachian tube function, or as an inflammatory response following acute otitis media (2). Pneumatic otoscopy has been recommended as the primary method for diagnosing OME because reduced tympanic membrane mobility correlates most closely with the presence of fluid in the middle ear (3). When the diagnosis of OME is uncertain, tympanometry or acoustic reflectometry should be considered as an adjunct to pneumatic otoscopy. Tympanometry with a standard $226-\mathrm{Hz}$ probe tone is reliable for infants 4 months or older and has a good interobserver agreement of curve patterns in routine clinical practice (4). The acoustic reflex (AR) is an involuntary muscle contraction that occurs in the middle ear in response to high-intensity sound stimuli or when the person starts to vocalize. If there is hearing loss, either conductive or sensorineural, of $65 \mathrm{~dB}$ hearing level $(\mathrm{HL})$ or greater in the stimulated ear, the reflex will likely be absent (5). The quantification of tympanometric measurements facilitates the development of appropriate standards for comparing tympanometric data among clinics. These measurements include static compliance (SC), volume of external ear canal, tympanometric gradient (GR), and tympanometric peak pressure (TPP) (6). 
This study aimed to evaluate whether the otoscopic examination findings are consistent with quantitative tympanometric parameters (especially GR) and AR in patients who had a tympanogram peak in the negative range after a recent history of OME. The study also discusses the role of the quantitative tympanometric parameters (especially GR) and AR as heralds of the healing process in patients with OME.

\section{MATERIALS and METHODS}

\section{Enrollment and Study Design}

This study enrolled patients who met the study criteria, from January 2017 to March 2019, after approval of the institutional review board. In this retrospective case-control study, patient consent form was not required. Patients aged between 4 and 14 years and with a recent history of OME with a negative peak at tympanogram were included in the study. Patients who had a pure-tone average $(500 \mathrm{~Hz}, 1000 \mathrm{~Hz}, 2000 \mathrm{~Hz}$, and 3000 $\mathrm{Hz}$ ) worse than $25 \mathrm{~dB}$ of $\mathrm{HL}$, difficulty in obtaining the hearing thresholds, advanced tympanic membrane retraction, middle ear effusion, or neurological and craniofacial anomalies were excluded from the study. Pneumatic otoscopy was performed to exclude fluid in the middle ear and to determine if there was a tympanic membrane retraction.

After the inclusion of patients into the study, 2 groups were created according to tympanic membrane findings. The examination of the tympanic membrane was carried out using Barr's classifications (7), in which the tympanic membrane was divided into areas including anterior to the manubrium malleus (I), posterior superior to the manubrium malleus (II upper), and posterior inferior to the manubrium malleus (II lower) and attic (III). The touching of the eardrum with incus and head of malleus was graded as a first degree (slight) retraction in all areas except in II lower in which first degree (slight) retraction was described as an eardrum dislocated inward without connection of promontory. Patients with normal eardrums were included in group $B$, whereas patients who had the first-degree retraction either throughout the eardrum or in any subregion were included in group $A$. The quantitative tympanometric parameters were noticed in addition to AR through an im-

\section{Main Points:}

- This study was designed to investigate the importance of quantitative tympanometric findings in estimating the prognosis of OME. Particularly, the study of AR in the selected patients was a new entity.

- Although it is well known that tympanometric quantitative values (eg, GR, TPP) are the most discussed topics of $O M E$, in this study, we tried to ascertain whether GR and AR have a prognostic value.

- Patients with OME who progressed to either full or near-recovery stage were divided into 2 groups, and the tympanometric values were evaluated, especially the GR and AR between these groups.

- On the basis of the results, it can be concluded that obtaining $A R$ is mostly related to a good $G R$ value and that $G R$ is a valuable parameter in predicting the prognosis of OME. pedance audiometer with a 226- Hz probe tone (AT235, Interacoustics, Denmark). GR may be calculated in 2 measurement units, milliliter and daPa. GR described as the tympanogram width at half the height of the peak of the SC was shown with pressure in this study. At any frequency, obtaining an ipsilateral AR was accepted as AR positivity. Tympanometric values (TPP, SC, and GR) and AR of patients in each group were compared statistically.

\section{Statistical Analysis}

The values obtained were entered into a computer-based spreadsheet and the data analyses were carried out using the SPSS software for Windows version 9.0; a $P$ value of $\leq .05$ was considered significant. The quantitative tympanometric data in both the groups were compared with the independent ttest, whereas the AR differences were compared with the chisquare test.

\section{RESULTS}

The mean age of the 89 patients who enrolled in the study was $9.17 \pm 2.26$ years; 45 were girls (mean age, $8.38 \pm 1.65$ years) and 44 were boys (mean age, $10.00 \pm 2.55$ years). In 50 of the 89 patients, both ears were included in the study. A total of 139 tympanometric measurements were obtained from 89 patients, of which 66 were in group A (abnormal tympanic membrane) and 73 were in group $B$ (normal tympanic membrane).

The mean SC was $0.54 \pm 0.33 \mathrm{~mL}$ in group $A$ and $0.55 \pm 0.32 \mathrm{~mL}$ in group $B(p=.45)$. The mean values of TPP were $-129.33 \pm 77.48$ daPa and $-38.64 \pm 57.98 \mathrm{daPa}(p=.001)$ in group A and group $\mathrm{B}$, respectively, and the mean values of $\mathrm{GR}$ were $157.06 \pm 92.85 \mathrm{daPa}$ and $103.60 \pm 28.5 \mathrm{I} \mathrm{daPa}(p=.00 \mathrm{I})$ in group $\mathrm{A}$ and group $\mathrm{B}$, respectively.

Within the 139 measurements, AR was obtained in 65 measurements (46.8\%); however, it was not detected in the remaining 74 measurements (53.2\%). The mean GR of the measurements in cases with AR positivity was $114.20 \pm 59.99$ daPa, whereas the mean GR of the measurements in cases with AR negativity was $141.97 \pm 79.46$ daPa $(p=.001)$. In group $A$, 32 out of 66 measurements (48.5\%) of AR were positive, and in group $B, 33$ out of 73 measurements (45.2\%) of AR were positive $(p=.44)$. The relationship between $A R$ and tympanometric quantitative parameters is shown in Table I for both groups individually and combined.

\section{DISCUSSION}

Tympanometry provides an objective assessment of tympanic membrane mobility, Eustachian tube function, and middle ear function by measuring the amount of sound energy reflected back when a small probe is placed in the ear canal $(8,9)$. Tympanometric curves, or tracings, are classified into 3 main types-type A (low probability of effusion) with a sharp peak and normal middle ear pressure, type B (high probability of effusion) with no discernible peak and a flat tracing, and type $C$ (Eustachian tube dysfunction/middle ear pathology) with a discernible peak and negative middle ear pressure (I0). In addition to these tympanometric curves, quantitative parameters of tympanometry give valuable information about the condition of the middle ear and eardrum. TPP is the ear canal pressure at which the peak of the tympanogram occurs. The peak 


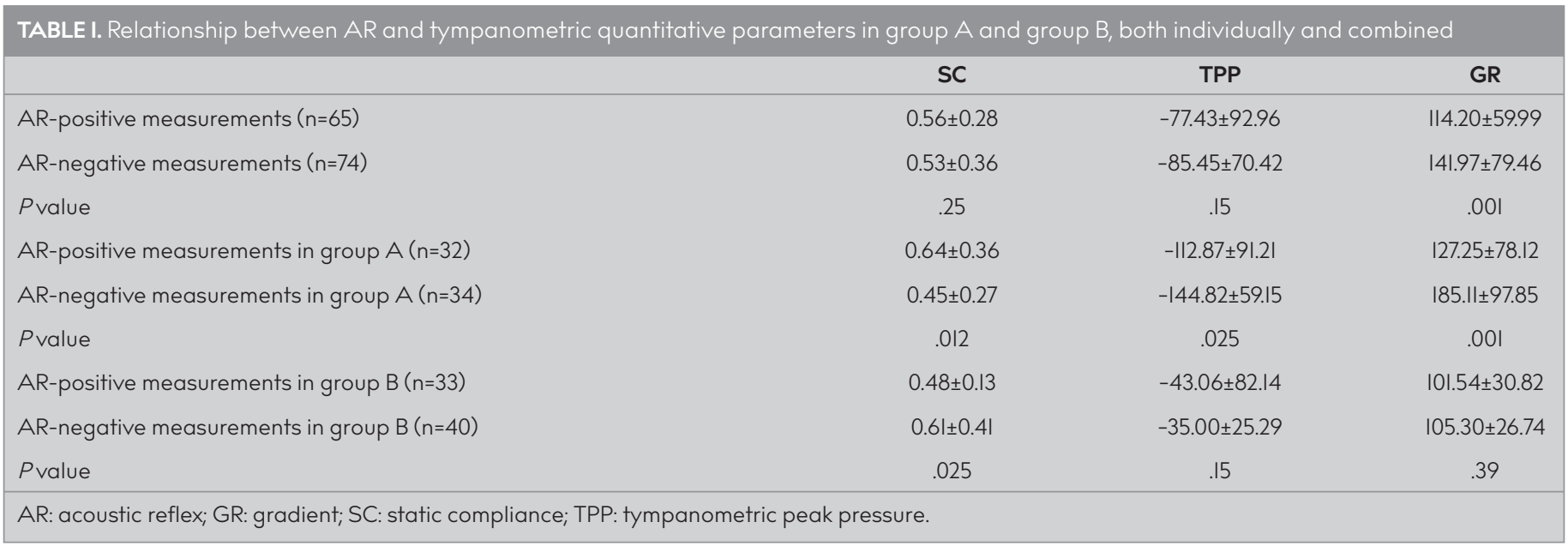

at or less from - 100 daPa indicates a type C curve. The SC is the length of the vertical peak of the tympanic tracing that can be obtained by extraction of the external ear volume from the total volume. The height decreases when the SC is abnormally low, which occurs when there is stiffness in the middle ear, and it is associated with disorders such as ossicular chain fixation, cholesteatoma, otosclerosis, and fluid in the middle ear, the latter being the most common cause in children (II). In this study, the TPP values of the 2 groups were in accordance with the examination findings of the eardrums. As expected, there was no difference in SC between the groups, and this result was associated with the minimal retraction of the eardrum without a decrease in middle ear volume. Therefore, it could be concluded that TPP is more descriptive than SC during the recovery stage of OME.

GR describes the sharpness of the tympanogram peak. This calculation was popularized when it was observed that tympanograms frequently were broadly rounded in ears with OME. Duzer et al. (12) described that GR value, which was measured as a unit of milliliter, was an accessory diagnostic parameter in addition to the TPP and SC values in patients with OME. Nozza et al. $(13,14)$ conducted studies in participants who were between the ages of 3 and 16 years and presented with the mean value of GR of 104 daPa (ranging between 60 and $168 \mathrm{daPa}$ ). Unlike the study conducted by Duzer et al, GR was calculated as a unit of daPa in this study; the difference of GR between the 2 groups was so significant that the mean GR value was $157.06 \pm 92.85 \mathrm{daPa}$ and $103.60 \pm 28.51 \mathrm{daPa}$ in groups $A$ and $B$, respectively. Both GR and TPP were revealed hitherto the 2 most important measurements to determine if an OME was in the recovery period.

AR measurement requires relatively healthy tympanic membrane, middle ear ossicles, and HL. In addition, the healthy neural way of reflex arc is important in obtaining $A R$, which extends from the cochlear nerve to the stapedial branch of the facial nerve (5). A positive $A R$ is quite common in individuals with normal $\mathrm{HL}$ (I5). When all cases were separated into 2 subgroups on the basis of AR positivity, no statistically significant differences were observed in the values of SC and TPP; however, significant differences were observed in the 2 groups in GR. As depicted in Table I, there was a statistically significant difference between the cases with positive AR and negative AR when a compari- son was performed on the basis of the 3 parameters (SC, TPP, and $G R$ ) in group $A$. In group $B$, the statistical difference of SC between the cases described as positive $A R$ and negative $A R$ was significant, whereas the other 2 parameters were not; however, SC was unreasonably higher in patients without reflexes. In group $B$, the pattern of TPP values between the cases with positive $A R$ and negative AR was similar to the pattern of SC values, but gradient was higher in AR-negative patients as expected. According to those beforementioned results, which are also briefed in Table I, it may be logical to think that GR is more effective in creating $A R$ than other parameters.

Marchant et al. (16) conducted a prospective study in which AR thresholds were high in patients with OME. In another study, AR was observed to be less sensitive to acute otitis media than $O M E$ and using $A R$ in the diagnosis of OME was valuable in addition to pneumatic otoscopy (17). When the 2 groups ( $A$ and $B$ ) were compared for the presence and absence of $A R$, there was no difference between the groups, and sufficiently positive $A R$ could not be obtained in group $B$ as expected. This could be explained by the presence of subclinical middle ear inflammation in group $B$ even with normal tympanic membrane. In addition, not only a healthy ear but also the whole pathways of reflex arc have to be intact to obtain an AR. Even if the reflex did not show a prognostic value, further studies with broad participation are required to determine its role in OME given that in this study, the cases with positive AR of group B had better GR value than those who had no reflex.

In conclusion, GR and TPP, together, are reliable tympanometric quantitative parameters in the diagnosis and follow-up of patients with OME who are progressing to the full recovery stage. There is no prognostic value of AR for patients with type C tympanograms with minimal tympanic membrane retraction during the healing stage of OME. However, to fully demonstrate the role of $A R$ during the healing stage of $O M E$, prospective studies with a control group are needed. AR positivity depends on many factors; as discussed in this study, the value of GR is the most prominent determinant in obtaining AR. Using GR is important for patients with OME who progress to complete healing.

Ethics Committee Approval: Ethics committee approval was received for this study from the ethics committee of Firat University (Approval date: 0l/29/2000, No: 13281952-903.07.99-E.670) 


\section{Informed Consent: N/A}

Peer-review: Externally peer-reviewed.

Author contributions: Concept - C.H.; Design - C.H.; Supervision - C.H., S.N.; Resource - C.H., S.N.; Materials - C.H., S.N.; Data Collection and/or Processing - C.H., S.N.; Analysis and/or Interpretation - C.H., S.N.; Literature Search - C.H.; Writing - S.N.; Critical Reviews - S.N.

Conflict of Interest: Authors have no conflicts of interest to declare.

Financial Disclosure: The authors declared that this study has received no financial support.

\section{REFERENCES}

I. Karma PH, Penttila MA, Sipila MM, Kataja MJ. Otoscopic diagnosis of middle ear effusion in acute and non-acute otitis media. I. the value of different otoscopic findings. Int J Pediatr Otorhinolaryngol 1989; 17(1): 37-49. [Crossref]

2. Paradise JL, Rockette HE, Colborn DK, Bernard BS, Smith CG, KursLAsky M, et al. Otitis media in 2253 Pittsburgh-area infants: prevalence and risk factors during the first two years of life. Pediatrics 1997; 99(3): 318-33. [Crossref]

3. Rosenfeld RM, Culpepper L, Doyle KJ, Grundfast KM, Hoberman A, Kenna MA, et al. Clinical practice guideline: otitis media with effusion. Otolaryngol Head Neck Surg 2004; 130: 95-II8. [Crossref]

4. Palmu A, Puhakka H, Rahko T, Takala AK. Diagnostic value of tympanometry in infants in clinical practice. Int J Pediatr Otorhinolaryngol 1999; 49(3): 207-13. [Crossref]

5. Campbell CMK, Peck JE. Audiology. Lee KJ, Chan Y, Das S. editors. Essential Otolaryngology Head and Neck Surgery. USA: McGraw Hill; 2012.p.24-67.

6. Fowler CG, Shanks JE. Tympanometry. Katz J. editor. Handbook of Clinical Audiology. Philadelphia: Lippincott Williams $\bar{\alpha}$ Wilkins; 2002: 175-204.
7. Barr GD. A Working classification of retraction for the whole tympanic membrane. Int J Otorhinolaryngol Head Neck Surg 2013; 2: 143-7. [Crossref]

8. Gurgel RK, Jackler RK, Dobie RA, Popelka GR. A new standardized format for reporting hearing outcomes in clinical trials. Otolaryngol Head Neck Surg 2012; 147(5): 803-7. [Crossref]

9. Rosenfeld RM, Shin JJ, Schwartz SR, Coggins R, Gagnon L, Hackell $J M$, et al. Clinical practice guideline: Otitis media with effusion (Update). Otolaryngol Head Neck Surg 2016; 154(2): 20I-14. [Crossref]

10. Margolis RH, Hunter LL. Acoustic immittance measurements. RJ Roeser, M Valente, H Hosford-Dunn. editors. Audiology Diagnosis. New York: Thieme Medical Publishers; 2000.p.38I-423.

II. Margolis RH, Shanks JE. Tympanometry. Katz J. Editor. Handbook of Clinical Audiology. Baltimore: Williams $₫$ Wilkins; 1985.p.438-75.

12. Duzer S, Sakallioglu O, Akyigit A, Polat C, Cetiner H, Susaman N. Values range of tympanometric gradient in otitis media with effusion. J Craniofac Surg 2017; 28(3): 283-6. [Crossref]

13. Nozza RJ, Bluestone CD, Kardatze D, Bachman R. Towards the validation of aural acoustic immittance measures for diagnosis of middle ear effusion in children. Ear Hear 1992; 13(6): 442-53. [Crossref]

14. Nozza RJ, Bluestone CD, Kardatze D, Bachman R. Identification of middle ear effusion by aural acoustic immittance measures for diagnosis of middle ear effusion in children. Ear Hear 1994; 15(4): 31023. [Crossref]

15. McGregor KD, Flamme GA, Tasko SM, Deiters KK. Acoustic reflexes are common but not pervasive: evidence using a diagnostic middle ear analyser. Int J Audiol 2017; 57(2): 42-50. [Crossref]

16. Marchant CD, McMillan PM, Shurin PA, Johnson CE, Turczyk VA, Feintein CE. Objective diagnosis of otitis media in early infancy by tympanometry and ipsilateral acoustic reflex thresholds. J Pediatr 1996; 109(4): 590-5. [Crossref]

17. Takata GS, Chan LS, Morphew T, Mangione-Smith R, Morton SC, Shekelle P. Evidence assessment of the accuracy of methods of diagnosing middle ear effusion in children with otitis media with effusion. Pediatrics 2003; II2: 1379-85. [Crossref] 